\title{
High Sensitivity C-Reactive Protein as Atherogenic Marker Among Type 2 Diabetes
}

\author{
Abdelmarouf H. Mohieldein \\ Marghoob Hasan \\ Department of Medical laboratories. College of Applied Medical \\ Sciences. Qassim University. Kingdom of Saudi Arabia \\ Mahmoud I. El-Habiby \\ Medical Laboratory Sciences Department, Al-Aqsa University, \\ Gaza, Palestine
}

Doi: 10.19044/esj.2017.v13n33p403 URL:http://dx.doi.org/10.19044/esj.2017.v13n33p403

\begin{abstract}
Background: People with type 2 diabetes are threefold affected by cardiovascular disease (CVD) compared with non-diabetics. Many studies reported the absence of traditional CVD risk factors in a substantial portion of individuals experiencing clinical vascular events. Novel risk markers for CVD are often said to add independent predictive value for risk prediction.

Objective: In the present study we evaluated different CVD risk factors based on high-sensitivity C-reactive (hs- CRP) protein quartiles among diabetics and non-diabetics population.

Methods: In this population- based cross- sectional study, we recruited a total of one-hundred and nine participants (64 type 2 diabetics and 45 healthy controls). Venous blood sample collected from each subject. Body weight and height were measured and body mass index (BMI) was calculated. Biochemical analytes were measured according to standard procedures. Data analyzed using SPSS software.

Results: Mean serum hs-CRP levels were significantly higher among diabetics $(2.3 \mathrm{mg} / \mathrm{l})$ compared to controls $(1.8 \mathrm{mg} / \mathrm{l} ; \mathrm{P}=0.019)$. Moreover, the 3 rd \& 4th quartiles of hs-CRP were characterized by more frequency of diabetes as well as hypertension. The percent of participants with diabetes or hypertension seemed positively related to hs CRP concentrations. Lipid profile analysis revealed the highest levels of LDL-C and Apo B in 4th quartile hs-CRP. In addition, participants in the 4th quartile hs-CRP were characterized by the highest age, BMI, plasma glucose. However, there was no clear association between levels of hs-CRP and the HbA1c, TC, TG, HDL-C, and Apo A1.
\end{abstract}


Conclusion: Measurement of hs-CRP in diabetic patients might provide useful information for development of atherosclerosis and cardiovascular disease and help in early intervention.

Keywords: Type 2 diabetes, cardiovascular disease, risk factors, inflammation, high-sensitivity C-reactive protein

\section{Introduction}

Type 2 diabetes (T2DM) consists of progressive hyperglycemia, insulin resistance, and pancreatic $\beta$-cell failure (Lin \& Sun, 2010). People with T2DM are reported to be threefold affected by cardiovascular diseases (CVD) compared with those without diabetes (Fonseca, Desouza, Asnani, \& Jialal, 2004), (Mohieldein, Abdalla, \& Hasan, 2014). Although traditional CVD risk factors, such as hypertension and hypercholesterolemia are used to assess CVD risk, many have reported their absence in a substantial portion of individuals experiencing clinical vascular events (de Ferranti \& Rifai, 2007). In fact, up to half of those having their first coronary event does not have traditional CVD risk factors (Shrivastava, Singh, Raizada, \& Singh, 2015). Moreover, diabetic patients have not benefited from the advances in the management of coronary heart disease (CHD) and/or its risk factors that have resulted in a decrease in mortality for CHD patients without diabetes (Fonseca, Desouza, Asnani, \& Jialal, 2004). This convergence of clinical findings supporting the idea that there must be other factors influencing the development of CVD end points. Clearly, a more aggressive approach is needed to discover additional predictors of risk and incorporate them into the traditional risk assessment of CVD (D'Amore, 2005). Among the candidate serum markers that might add information to clinical risk assessment is high sensitivity C-reactive protein (hs-CRP) measurement which has the most potential for clinical use (de Ferranti \& Rifai, 2007), (Yousuf et al., 2013), (Grad \& Danenberg, 2013). C-reactive protein (CRP) is a $120 \mathrm{kDa}$ acutephase protein which is produced mainly in the liver in response to IL-6 secretion (Ahmed, Jadhav, Hassan, \& Meng, 2012), (Ferri et al., 2007). CRP is a member of the pentraxin family of proteins that binds to the Cpolysaccharide of Streptococcus pneumoniae (Gang et al., 2012).

Novel risk markers for CVD are often said to add independent predictive value for risk prediction, based on the finding of a significant relative risk after adjustment for traditional risk factors (Lloyd-Jones, Liu, Tian, \& Greenland, 2006). In the present report we evaluated different CVD risk factors based on hs-CRP quartiles. 


\section{Materials and Methods \\ Study design and subjects}

This is a population- based cross- sectional study of one-hundred and nine participants, comprising 64 type 2 diabetics and 45 healthy controls. Type 2 diabetics were identified according to American Diabetes Association criteria (fasting plasma glucose level $\geq 126 \mathrm{mg} / \mathrm{dl}$ (ADA, 2010)) or self-reported use of diabetic medication. Healthy non-diabetic subjects were recruited from the community; they neither had been diagnosed as diabetes nor use hypoglycaemic medication; or any history of known disease.

\section{Blood sampling}

Venous blood sample collected from each subject after an overnight fasting in one heparinized vacutainer $(4 \mathrm{ml})$ and one plain vacutainer $(4 \mathrm{ml})$ to obtain plasma and serum respectively. $\mathrm{HbA}_{1 \mathrm{c}}$ was performed and after centrifugation at $3000 \mathrm{rpm}$ for $15 \mathrm{~min}$, aliquots of plasma and serum were separated and stored at $-80^{\circ} \mathrm{C}$ until analysis.

\section{Anthropometric Measurements}

Body weight and height were measured by trained research assistants for all participants. Weight was measured using calibrated electronic weighing scales (Proton Digital Scale, Model PHC 309 MD) and height was measured using a Portable Height Scale (Mentone Educational, Model PE087, Australia).

Body Mass Index (BMI) was used to estimate the degree of obesity, and was calculated as weight (in kilograms) divided by height (in metres) squared using BMI calculator in the website:

https://www.nhlbi.nih.gov/health/educational/lose_wt/BMI/bmi-m.htm

\section{Measurement of blood glucose}

Blood glucose was determined based on the glucose oxidase peroxidase (GOD- POD) method using commercial kits purchased from Human Diagnostics (Wiesbaden, Germany) using Hospitex Eos Bravo clinical chemistry analyzer. The glucose was determined after enzymatic oxidation in the presence of glucose oxidase. The formed hydrogen peroxide reacted under catalysis of peroxidase with phenol and 4-aminophenazone to a red-violet quinoneimine dye as indicator. The test linearity was up to 700 $\mathrm{mg} / \mathrm{dl}$.

\section{Measurement of glycated hemoglobin}

Glycated hemoglobin $\left(\mathrm{HbA}_{1 \mathrm{c}}\right)$ was measured on whole blood samples by an immunoturbidimetric method using commercial kit (ACC16-048, Vital 
Diagnostic, Italy). Mouse antihuman $\mathrm{HbA}_{1 \mathrm{c}}$ monoclonal antibody was added and latex-HbA $\mathrm{H}_{1 \mathrm{c}}$-mouse anti human monoclonal antibody complex was formed. Agglutination was formed when goat anti-mouse IgG polyclonal antibody interacts with monoclonal antibody. The amount of agglutination was proportional to the amount of $\mathrm{HbA}_{1 \mathrm{c}}$ adsorbed onto the surface of latex particles. The amount of agglutination was measured as absorbance. The assay range was $0-15 \%$ and samples equal to or more than $15 \%$ were diluted with saline solution and retested.

\section{Measurement of lipid profile}

Serum total cholesterol (TC), triglycerides (TG) and high-density lipoprotein cholesterol (HDL-C) were analyzed using enzymatic methods with commercial kits purchased from Human Diagnostics (Wiesbaden, Germany).

TC was determined based on the cholesterol oxidase- peroxidase (GHOD- POD) method. Cholesterol esterase catalyzed the hydrolysis of cholesterol esters to produce cholesterol which was oxidized by cholesterol oxidase to yield hydrogen peroxide. In a couple reaction catalyzed by peroxidase, quinoneimine dye (red) was formed and the absorbance at 546 $\mathrm{nm}$ was proportional to concentration of cholesterol in sample.

TG was determined based on the glycerol-3-phosphate oxidaseperoxidase (G PO- POD) method. The TG was determined after enzymatic hydrolysis with lipases. Indicator was quinoneimine formed from hydrogen peroxide, 4-amino-antipyrine and 4-chlorophenol under the catalytic influence of peroxidase

HDL-C was determined based on phosphotungstic-precipitation method. Briefly, phosphotungstic acid and magnesium ions specifically precipitated low and very low density lipoproteins. After centrifugation; the cholesterol content of the HDL was determined in the supernatant.

Provided serum TG concentrations were less than $400 \mathrm{mg} / \mathrm{dl}$, the low-density lipoprotein-cholesterol (LDL-C) was calculated using Friedewald formula: [LDL-C = TC - HDL-C - TG/5 (mg/dl)].

\section{Measurement hs-CRP}

Serum hs-CRP concentration was assayed by a latex immunoturbidimetric method using Turbi Quick analyzer (vital Diagnostics, Italy) with kits purchased from the same company (Ref: ACC16-025). The latex particles coated with specific anti-human CRP were agglutinated when mixed with samples containing CRP. The agglutination caused an absorbance change, dependent upon the CRP contents of the patient sample that was quantified by comparison from a calibrator of known CRP concentration. 
The linearity limit was up to $5 \mathrm{mg} / \mathrm{l}$. The lower detection limit of the assay was $0.05 \mathrm{mg} / \mathrm{l}$. The intra-assay coefficient of variation of the CRP levels was $2.0 \%$ at $3.0 \pm 0.06 \mathrm{mg} / \mathrm{l}$, while the inter-assay coefficient of variation was $3.7 \%$ at $3.0 \pm 0.11 \mathrm{mg} / \mathrm{l}$. CRP levels were categorized into quartiles based on the distribution among the controls.

\section{Measurement apolipoprotein A1 and Apo B}

Sera ApoA1 and Apo B were measured on Turbi Quick analyzer from Vital Diagnostics, Italy. It was based on latex enhance Immunoturbidimetric method. We used Apo A1 -B dual control to assess the performance of the analyzer. The typical measuring range was up to 700 $\mathrm{mg} / \mathrm{dl}$ for both parameters. Sample and reagents were brought to room temperature, card provided with reagent were inserted into the analyzer, after some time, the analyzer became ready for testing, we run the control in control mode and sample in sample mode.

\section{Measurement of blood pressure}

Systolic blood pressure (SBP) and diastolic blood pressure (DBP) were measured prior to drawing blood samples in the sitting position, using a standard mercury sphygmomanometer following standard procedure (Milne \& Pinkney-Atkinson, 2007). Two consecutive readings were recorded for each of SBP and DBP and the averages were used. Subjects were defined as hypertensive if their systolic blood pressure $\geq 140 \mathrm{~mm} \mathrm{Hg}$ or diastolic blood pressure $\geq 90 \mathrm{~mm} \mathrm{Hg}$

\section{Statistical Analysis}

Data were analyzed using the Windows based statistical package for social sciences (SPSS) software (version 17, Chicago, IL, USA). Results were expressed as mean \pm standard deviation or number (\%) where appropriate. Comparison between diabetics and controls was performed with unpaired t-tests (for numerical data) and chi-square (for categorical data). The $P$ values $<0.05$ was considered as statistically significant.

\section{Ethical consideration}

The protocol of current study was carried according to the Helsinki declaration guidelines. Verbal consent was obtained from each subject after thoroughly explanation the goals of the study. Participation was voluntary and confidentiality of all participants was maintained as no names were requested 


\section{Results}

\section{Baseline demographic and clinical characteristics of the study diabetics and controls}

A total of one hundred and nine subjects were included in this study of which sixty-four were type 2 diabetics and forty-five healthy non-diabetic subjects. In the patient group, the mean $\pm \mathrm{SD}$ values for age, HDL-C and ApoA1 were $55.5 \pm 9.5$ years, $37.8 \pm 3.3 \mathrm{mg} / \mathrm{dl}$ and $111.5 \pm 15.0 \mathrm{mg} / \mathrm{dl}$ while for subjects in control group were $45.9 \pm 10.6$ years $48.8 \pm 4.1 \mathrm{mg} / \mathrm{dl}$ and $130.1 \pm 26.3 \mathrm{mg} / \mathrm{dl}$ respectively. Moreover, Patients were characterized by significantly higher age, BMI, plasma glucose, dyslipidemia when compared to controls.

Mean serum hs-CRP levels were significantly higher among diabetics (2.3 mg/l) compared with controls $(1.8 \mathrm{mg} / \mathrm{l} ; \mathrm{P}=0.019)$. The clinical characteristics and laboratory values in study participants with and without diabetes were presented in Table 1.

Table 1. Baseline clinical and laboratory characteristics of the study population

\begin{tabular}{|c|c|c|c|}
\hline Variable & Controls $(\mathrm{n}=45)$ & Diabetics $(\mathrm{n}=64)$ & $p$-value \\
\hline Gender (Male/Female) & $23 / 22$ & $22 / 42$ & 0.081 \\
\hline Smoking (Yes/No) & $10 / 35$ & $04 / 60$ & $0.014^{*}$ \\
\hline Education (illiterate/educated) & $14 / 31$ & $40 / 24$ & $0.000^{*}$ \\
\hline Hypertension (Yes/No) & $09 / 36$ & $36 / 28$ & $0.000^{*}$ \\
\hline Age, years & $45.9 \pm 10.6$ & $55.5 \pm 9.5$ & $0.000^{*}$ \\
\hline Body Mass Index, Kg/m ${ }^{2}$ & $28.9 \pm 5.7$ & $31.9 \pm 6.6$ & $0.019^{*}$ \\
\hline Plasma glucose, mg/dl & $98.3 \pm 8.3$ & $225.8 \pm 14.5$ & $0.000^{*}$ \\
\hline HbA $_{1 \mathrm{c}}, \%$ & $6.4 \pm 1.3$ & $8.3 \pm 2.2$ & 0.222 \\
\hline hs-CRP, mg/l & $1.8 \pm 0.7$ & $2.3 \pm 1.4$ & $0.019^{*}$ \\
\hline Total Cholesterol, mg/dl & $183.6 \pm 13.8$ & $206.1 \pm 20.8$ & $0.001^{*}$ \\
\hline Triglycerides, mg/dl & $133.5 \pm 5.7$ & $156.2 \pm 8.6$ & $0.032^{*}$ \\
\hline HDL cholesterol, mg/dl & $48.8 \pm 4.1$ & $37.8 \pm 3.3$ & $0.000^{*}$ \\
\hline LDL cholesterol, mg/dl & $108.1 \pm 11.3$ & $137.1 \pm 13.1$ & $0.001^{*}$ \\
\hline Apo A1, mg/dl & $130.1 \pm 26.3$ & $111.5 \pm 15.0$ & $0.005^{*}$ \\
\hline ApoB, mg/dl & $89.9 \pm 15.8$ & $97.8 \pm 18.3$ & 0.097 \\
\hline
\end{tabular}

Values are expressed in mean \pm SD or number.

$\mathrm{P}$-values for comparison between controls and diabetics were generated by chi-square (for categorical data) and unpaired t-tests (for numerical data)

\section{Risk factor differences across quartiles of hs-CRP among study participants}

Data from study participants showed that the hs-CRP levels were $\leq 1.342 \mathrm{mg} / \mathrm{l}$ (quartile 1), $1.343-1.721 \mathrm{mg} / \mathrm{l}$ (quartile 2), $1.722-2.447 \mathrm{mg} / \mathrm{l}$ (quartile 3), and $\geq 2.448 \mathrm{mg} / \mathrm{l}$ (quartile 4). The third and fourth quartiles of hs-CRP were characterized by more frequency of diabetes as well as hypertension. The percent of participants with diabetes or hypertension apparently seemed to be positively related to hs-CRP concentrations. 
In the highest quartile of hs-CRP levels $(\geq 2.448 \mathrm{mg} / \mathrm{l})$, lipid profile analysis revealed the highest levels of LDL-C and Apo B compared with that in the lowest quartile of hs-CRP levels $(<1.343 \mathrm{mg} / \mathrm{l})$

Moreover, participants in the fourth quartile of hs-CRP were characterized by the highest age, BMI, plasma glucose. However, there was no clear association between levels of hs-CRP and the HbA1c, TC, TG, HDL-C, and Apo A. The distribution of the clinical, biochemical, and anthropometric characteristics across quartiles of serum hs-CRP was shown in Table 2.

Table 2. The differences in CVD risk factors based on hs-CRP quartiles

\begin{tabular}{|c|c|c|c|c|c|}
\hline & \multicolumn{4}{|c|}{ Quartile CRP (range, mg/l) } & \multirow{2}{*}{$\begin{array}{c}P- \\
\text { value }\end{array}$} \\
\hline Risk factor & $\begin{array}{c}1^{\mathrm{st}} \cdot \\
(0.531- \\
1.342)\end{array}$ & $\begin{array}{c}2^{\text {nd }} \cdot \\
(1.343- \\
1.721) \\
\end{array}$ & $\begin{array}{c}3^{\text {rd }} . \\
(1.722- \\
2.447)\end{array}$ & $\begin{array}{c}4^{\text {th }} \cdot \\
(2.448- \\
9.738)\end{array}$ & \\
\hline Sample size, $n$ & 26 & 27 & 29 & 27 & \\
\hline Age, years & $49.9 \pm 12.8$ & $52.8 \pm 11.1$ & $49.0 \pm 9.2$ & $54.7 \pm 10.4$ & $0.004^{*}$ \\
\hline Diabetes, n (\%) & $13(50)$ & $13(48.1)$ & $19(65.5)$ & $19(70.4)$ & 0.248 \\
\hline Hypertension, $\mathrm{n}(\%)$ & $8(30.8)$ & $12(44.4)$ & $11(37.9)$ & $14(51.9)$ & 0.441 \\
\hline Weight, $\mathrm{Kg}$ & $70.5 \pm 11.6$ & $74.8 \pm 17.1$ & $80.3 \pm 13.2$ & $85.1 \pm 20.4$ & $0.008^{*}$ \\
\hline Height, $\mathrm{cm}$ & $158.3 \pm 22.1$ & $159.2 \pm 12.1$ & $155.8 \pm 15.6$ & $160.7 \pm 7.9$ & 0.687 \\
\hline BMI, $\left(\mathrm{Kg} / \mathrm{m}^{2}\right)$ & $28.1 \pm 8.4$ & $29.5 \pm 4.7$ & $33.1 \pm 5.9$ & $33.0 \pm 5.3$ & $0.046^{*}$ \\
\hline $\begin{array}{c}\text { Plasma glucose, } \\
\mathrm{mg} / \mathrm{dl}\end{array}$ & $159.8 \pm 21.6$ & $139.3 \pm 14.1$ & $195.2 \pm 18.3$ & $220.6 \pm 23.2$ & $0.015^{*}$ \\
\hline $\mathrm{HbA}_{1 \mathrm{c}}, \%$ & $8.5 \pm 2.2$ & $8.0 \pm 1.9$ & $8.2 \pm 2.0$ & $8.2 \pm 2.6$ & 0.964 \\
\hline Triglycerides, mg/dl & $145.1 \pm 14.8$ & $156.6 \pm 10.5$ & $137.2 \pm 8.2$ & $147.5 \pm 7.5$ & 0.635 \\
\hline $\begin{array}{c}\text { Total Cholesterol, } \\
\mathrm{mg} / \mathrm{dl}\end{array}$ & $193.9 \pm 22.5$ & $197.5 \pm 15.3$ & $201.8 \pm 24.5$ & $203.5 \pm 23.8$ & 0.196 \\
\hline $\begin{array}{l}\text { HDL cholesterol, } \\
\text { mg/dl }\end{array}$ & $42.5 \pm 6.3$ & $40.7 \pm 8.4$ & $43.2 \pm 6.9$ & $39.9 \pm 3.8$ & 0.681 \\
\hline $\begin{array}{c}\text { LDL cholesterol, } \\
\text { mg/dl }\end{array}$ & $122.4 \pm 9.2$ & $125.5 \pm 8.6$ & $131.2 \pm 6.4$ & $134.1 \pm 7.8$ & $0.026^{*}$ \\
\hline ApoA1, mg/dl & $115.0 \pm 8.5$ & $125.2 \pm 11.8$ & $115.1 \pm 17.6$ & $114.3 \pm 17.2$ & 0.630 \\
\hline ApoB, mg/dl & $92.7 \pm 17.6$ & $94.6 \pm 13.4$ & $92.39 \pm 14.2$ & $98.5 \pm 14.3$ & $0.052^{*}$ \\
\hline
\end{tabular}

P-values for comparison between hs-CRP quartiles were generated by chi-square (for categorical data) and unpaired t-tests (for numerical data)

\section{Discussion}

Cardiovascular diseases (CVD), leading cause of morbidity and mortality from infancy to old age, are increasing day by day due to over utilization of fats or due to genetic reasons (Upadhyay, 2015). CVD are the number one cause of death globally: more people die annually from CVDs than from any other cause (Al-Mawali, 2015). 
In this study, age, BMI, plasma glucose, hs-CRP, total cholesterol, triglycerides, and LDL-cholesterol were found to be significantly higher in the diabetic patients when compared with the nondiabetic group. However, HDL- cholesterol and Apo A1 were significantly low in the diabetics when compared to nondiabetic controls. It has been shown that patients with diabetes tend to have a higher body mass index and tend to be glucoseintolerant, insulin-resistant, and dyslipidemic, with high plasma triglyceride and low HDL cholesterol concentrations (Yasunari, Maeda, Nakamura, \& Yoshikawa, 2002).

Despite the irreplaceable utility of plasma lipid profiles in assessment of atherosclerotic risk, these profiles provide an incomplete picture. Indeed, many cardiovascular events occur in individuals with plasma cholesterol concentrations at or below the National Cholesterol Education Program thresholds (Packard \& Libby, 2008). Among the several biomarkers that have been proposed for cardiovascular risk stratification, hs-CRP appears to contribute to the identification of people at risk of developing CVD (Fonseca \& Izar, 2016). Data from the current study confirms that the high hs-CRP levels associated with diabetes, that is, the third and fourth hs-CRP quartiles characterized by high percent of diabetic patients compared to the lowest hsCRP quartiles. In accordance with our finding, Mahajan A et al (2009) reported that the median hs-CRP levels were reported to be significantly higher in diabetic patients as compared to nondiabetic $(\mathrm{P}<0.0001)$. Elevated hs-CRP was positively associated with type 2 diabetes (odds ratio, 1.66; 95\% confidence interval, 1.21-2.28; P 0.002). In the same line, the Women's Health Study documented that patients in the highest quartile of hs-CRP were 4-fold more likely to develop DM than patients in the lowest quartile during four years of follow-up (Mazidi, Toth, \& Banach, 2017). Recently a study in a Japanese population reported that elevated serum hs-CRP was associated with an increased degree of insulin resistance, after adjustment for traditional risk factors. Moreover, the association of serum hs-CRP with insulin resistance was stronger in obese subjects compared to normal weight subjects (Uemura et al., 2017). The same finding was documented from our study which evident an association between higher levels of hs-CRP quartiles and obesity illustrated by that participants in the fourth quartile of hs-CRP were characterized by significantly the highest BMI. In consistency with the latter finding, Lim et al (2010) reported higher quartiles of CRP levels were associated with higher BMI in both the men and the women diabetic patients. We can be explained such association of hs-CRP and obesity by that IL-6 and TNF- $\alpha$, which are proinflammatory cytokines secreted by adipose tissue, control synthesis and production of CRP (Saijo et al., 2004). 
Untreated hypertension increases the risk of heart failure, myocardial infarction, stroke, aneurysms, kidney failure and damage to retinal blood vessels (Subbiah, Chhabra, \& Mahajan, 2016). Moreover, recently it was reported that individuals who with treated blood pressure management strategy $(140-149 /<90 \mathrm{mmHg})$ have increased risk of CVD compared with those without hypertension (Nayor et al., 2017). Here we reported high percent of hypertension patients was found in fourth hs-CRP quartile which supported by Curb et al (2003) who documented that frequency of hypertension was as more than doubled in the top versus bottom quartile of hs-CRP (19.4 versus 8.4\%, P,0.001).

Data showed that the highest plasma glucose levels were found in the fourth quartiles hs-CRP compared to the lowest quartiles $(\mathrm{P}=0.015)$. In favor with this finding, Aronson D et al (2004) reported that diagnosed diabetes with impaired fasting glucose has the highest hs-CRP compared to subjects with normal fasting glucose. The authors concluded that hs-CRP levels increased continuously from the lowest quartile of normal fasting glucose level to impaired fasting glucose $(\mathrm{P}=0.002$ for trend within the nondiabetic range of fasting glucose) and to diabetes.

On the other hand, this study showed no significant association between hs-CRP quartile levels and the glycemic control marker, $\mathrm{HbA}_{1 \mathrm{c}}$. In contrast to our finding, recently one study reported that elevated baseline plasma CRP levels were associated with an increased risk of type 2 diabetes among those already with high HbA1c levels (Pan, Wang, Yuan, \& Koh, 2017). Furthermore, in line with a recent published work (Mazidi, Toth, \& Banach, 2017), our findings evident that lipid profile parameters LDL-C and Apo B were increasing across increasing quartiles of hs-CRP.

The characteristics of the fourth hs-CRP quartile with high frequency of diabetes, obesity, elevation of LDL-C and Apo B suggests coexistence of dysregulated lipid metabolism and inflammation in diabetic patients. Therefore, we may expect that patients with type 2 diabetes could be at increased risk for CVD and that hs-CRP might be a useful tool and predictor for CVD. The acute inflammatory response is an important component in the pathogenesis of myocardial injury during acute coronary syndrome and endothelial dysfunction is related especially with leukocyte recruitment during the formation of the atherosclerotic lesion. The firm union and transendothelial migration depend on the interaction between intercellular adhesion molecule-1 (ICAM-1), vascular cytoadhesion molecule-1 (VCAM1), and the integrins lymphocyte function antigen-1 (LFA-1, CD11a/ CD18) and very late activation antigen-4 (VLA-4, CD49/CD29) and the leukocytes (Macías, et al., 2003). Serum CRP stimulates endothelial cell expression of ICAM-1 and VCAM-1 which are important factors in the development of atherosclerosis and may play an important role in promoting the local 
inflammation within the atherosclerotic plaque (Amran et al., 2011). Moreover, elevated blood CRP levels may promote accumulation of monocytes in the atherogenic arterial wall by increasing chemotactic activities of monocytes in response to monocyte chemoattractant chemokine1 (MCP-1) via upregulation of the monocyte chemotaxis receptor CCR2 (Han et al., 2004).

\section{Conclusion}

Data from current study showed strong association of the some of the traditional risk factors for CVD with the highest quartile of hs-CRP levels compared with low levels. The fourth hs-CRP quartile was characterized with high prevalence of diabetes, obesity, elevation of LDL-C and Apo B which suggests coexistence of dysregulated lipid metabolism and inflammation in diabetic patients.

It has been reported that CVD onset may happen irrespective to lipid profile. Therefore, we may expect that patients with type 2 diabetes could be at increased risk for CVD which is one of the macrovascular complications of diabetes.

We deduced that hs-CRP measurement can provide useful and proactive information for development of cardiovascular diseases especially among type 2 diabetic patients. Thus hs-CRP can be incorporate into the traditional risk assessment of CVD which will help in early intervention to prevent the development of CVD among type 2 diabetes.

\section{References:}

1. Ahmed MS, Jadhav AB, Hassan A, \& Meng QH. (2012). Acute phase reactants as novel predictors of cardiovascular disease. ISRN Inflammation, 2012, 953461. doi: 10.5402/2012/953461.URL: https://www.hindawi.com/journals/isrn/2012/953461/

2. Al-Mawali A. (2015). Non-Communicable Diseases: Shining a Light on Cardiovascular Disease, Oman's Biggest Killer. Oman medical journal, 30(4), 227-228. doi: 10.5001/omj.2015.47 URL: https://www.ncbi.nlm.nih.gov/pmc/articles/PMC4561645/pdf/OMJD-15-00151.pdf

3. American Diabetes Association. (2010). Diagnosis and Classification of Diabetes Mellitus. Diabetes Care, 33, S62-S69.URL: https://www.ncbi.nlm.nih.gov/pmc/articles/PMC2797383/

4. Amran AA, Zakaria Z, Othman F, Das S, Al-Mekhlafi HM, \& Nordin NA. (2011). Changes in the vascular cell adhesion molecule1 , intercellular adhesion molecule- 1 and $\mathrm{c}$ reactive protein following administration of aqueous extract of piper sarmentosum on experimental rabbits fed with cholesterol diet. Lipids 
in health and disease, 10:2. doi: 10.1186/1476-511X-10-2.URL: https://lipidworld.biomedcentral.com/articles/10.1186/1476-511X$\underline{10-2}$

5. Aronson D, Bartha P, Zinder O, Kerner A, Shitman E, Markiewicz W, Brook GJ, \& Levy Y. (2004). Association between fasting glucose and C-reactive protein in middle-aged subjects. Diabetic medicine, 21(1):39-44

6. Curb JD, Abbott RD, Rodriguez BL, Sakkinen P, Popper JS, Yano K, \& Tracy RP. (2003). C-reactive protein and the future risk of thromboembolic stroke in healthy men. Circulation, 107(15), 2016-2020.

URL: http://circ.ahajournals.org/content/107/15/2016.long

7. D'Amore P J. (2005). Evolution of C-Reactive Protein as a Cardiac Risk Factor. Laboratory Medicine, 36(4), 234-238.URL: https://academic.oup.com/labmed/article/36/4/234/2657397/Evolutio n-of-C-Reactive-Protein-as-a-Cardiac-Risk.

8. de Ferranti SD \& Rifai N. (2007). C-reactive protein: a nontraditional serum marker of cardiovascular risk. Cardiovascular Pathology, $16(1)$ $14-21$.

URL: http://www.sciencedirect.com/science/article/pii/S105488070600071 8?via\%3Dihub.

9. Ferri C, Croce G, Cofini V, De Berardinis G, Grassi D, Casale R, Properzi G, \& Desideri G.(2007). C-reactive protein: interaction with the vascular endothelium and possible role in human atherosclerosis. Current Pharmaceutical Design, 13(16), 1631-45.

10. Fonseca FA \& Izar MC. (2016). High-sensitivity C-Reactive protein and cardiovascular disease across countries and ethnicities. Clinics (Sao Paulo), 71, 235-42

11. Fonseca V, Desouza C, Asnani S, \& Jialal I. (2004). Nontraditional risk factors for cardiovascular disease in diabetes. Endocrine Reviews, 25(1),153-75. URL: https://academic.oup.com/edrv/article-lookup/doi/10.1210/er.20020034.

12. Gang TB, Hammond DJ Jr, Singh SK, Ferguson DA Jr, Mishra VK, \& Agrawal A. (2012). The phosphocholine-binding pocket on C reactive protein is necessary for initial protection of mice against pne umococcal infection. The Journal of biological chemistry, 287(51), 43116-25. doi: 10.1074/jbc.M112.427310. URL: https://www.ncbi.nlm.nih.gov/pmc/articles/PMC4399050/.

13. Grad E. \& Danenberg HD. (2013). C-reactive protein and atherothrombosis: Cause or effect? Blood Reviews, 27(1), 23-9. doi: 10.1016/j.blre.2012.12.001.

URL: 
http://www.sciencedirect.com/science/article/pii/S0268960X1200075 6?via\%3Dihub.

14. Han KH, Hong KH, Park JH, Ko J, Kang DH, Choi KJ, Hong MK, Park SW, \& Park SJ. (2004). C-reactive protein promotes monocyte chemoattractant protein-1--mediated chemotaxis through upregulating $\mathrm{CC}$ chemokine receptor 2 expression in human monocytes. Circulation, 109 (21), 2566-71. URL: http://circ.ahajournals.org/content/109/21/2566.long

15. Lim LS, Tai ES, Mitchell P, Wang JJ, Tay WT, Lamoureux E, \& Wong TY. (2010). C-reactive protein, body mass index, and diabetic retinopathy. Investigative ophthalmology \& visual science, 51(9):4458-63. doi: 10.1167/iovs.09-4939

16. Lin Y \& Sun Z. (2010). Current views on type 2 diabetes. Journal of Endocrinology, 204(1), 1-11. doi: 10.1677/JOE-09-0260. URL: https://www.ncbi.nlm.nih.gov/pmc/articles/PMC2814170/.

17. Lloyd-Jones DM, Liu K, Tian L, Greenland P. (2006). Narrative review: Assessment of C

reactive protein in risk prediction for cardiovascular disease. Annals of Internal Medicine, 145(1), 35-42.URL:

http://annals.org/aim/article/725141/narrative-review-assessment-creactive-protein-risk-prediction-cardiovascular-disease.

18. Macías C, Villaescusa R, del Valle L, Boffil V, Cordero G, Hernández A, Hernández P, \& Ballester JM. (2003). Endothelial adhesion molecules ICAM-1, VCAM-1 and Eselectin in patients with acute coronary syndrome. Revista española de cardiología, 56(2), 137-44. URL:

http://www.revespcardiol.org/en/linkresolver/articuloresolver/13047669/

19. Mahajan A, Tabassum R, Chavali S, Dwivedi OP, Bharadwaj M, Tandon N, Bharadwaj D. (2009). High-sensitivity Creactive protein levels and type 2 diabetes in urban North Indians.

The Journal of clinical endocrinology and metabolism, 94(6), 21237. doi: $10.1210 /$ jc.2008-2754

20. Mazidi M, Toth PP, \& Banach M. (2017). C-reactive Protein Is Associated With Prevalence of the Metabolic Syndrome, Hypertension, and Diabetes Mellitus in US Adults. Angiology, 3319717729288. doi: 10.1177/0003319717729288

21. Milne FJ \& Pinkney-Atkinson VJ. (2007). Measuring and monitoring blood pressure. Professional Nursing Today, 11 (1), 16-19. URL: http://www.pntonline.co.za/index.php/PNT/article/view/105/110

22. Mohieldein AH, Abdalla KE, \& Hasan M. (2014). Lipoprotein (a) and atherogenic indices in Sudanese patients with type 2 diabetes. 
International Journal of Health Sciences (Qassim), 8(3), 237-46. URL: https://www.ncbi.nlm.nih.gov/pmc/articles/PMC4257359

23. Nayor M, Duncan MS, Musani SK, Xanthakis V, LaValley MP, Larson MG, Fox ER, \& Vasan RS. (2017). Incidence of cardiovascular disease in individuals affected by recent changes to US blood pressure treatment guidelines. Journal of Hypertension. doi: 10.1097/HJH.0000000000001570. URL: https://insights.ovid.com/pubmed?pmid=29084083 [Epub ahead of print

24. Packard RR \& Libby P.(2008). Inflammation in atherosclerosis: from vascular biology to biomarker discovery and risk prediction. Clinical Chemistry, 54(1), 24-38.URL: http://clinchem.aaccjnls.org/content/54/1/24

25. Pan A, Wang Y, Yuan JM, \& Koh WP. (2017). High-sensitive Creactive protein and risk of incident type 2 diabetes:

a casecontrol study nestedwithin the Singapore Chinese Health Study. BMC endocrine disorders, 17(1), 8. doi: 10.1186/s12902-017-0159-

5.

URL:

https://bmcendocrdisord.biomedcentral.com/articles/10.1186/s12902017-0159-5

26. Saijo Y, Kiyota N, Kawasaki Y, Miyazaki Y, Kashimura J, Fukuda M, \& Kishi R. (2004). Relationship between Creactive protein and visceral adipose tissue in healthy Japanese subjects. Diabetes, obesity \& metabolism, 6(4), 249-58. URL: http://onlinelibrary.wiley.com/doi/10.1111/j.14628902.2003.0342.x/abstract;jsessionid=4E9E6E317852D008C3E7DA 3C29167D22.f03t04

27. Shrivastava A K, Singh H V, Raizada A, \& Singh S K. (2015). Creactive protein, inflammation and coronary heart disease. Egyptian Heart Journal, 67, 89-97. URL: http://www.sciencedirect.com/science/article/pii/S111026081400117 3.

28. Subbiah A K, Chhabra Y K, \& Mahajan S. (2016). Cardiovascular disease in patients with chronic kidney disease: a neglected subgroup. Heart Asia, 8(2): 56-61. doi: 10.1136/heartasia-2016-010809

29. Uemura H, Katsuura-Kamano S, Yamaguchi M, Bahari T, Ishizu M, Fujioka M, \& Arisawa K. (2017). Relationships of serum highsensitivity C-reactive protein and body size with insulin resistance in a Japanese cohort. PLoS One, 12(6), e0178672. doi: 10.1371/journal.pone.0178672. eCollection 2017

30. Upadhyay RK. (2015). Emerging risk biomarkers in cardiovascular diseases and disorders. Journal of Lipids, 2015, 971453. doi: 
$10.1155 / 2015 / 971453$.

URL:

https://www.hindawi.com/journals/j1/2015/971453/

31. Yasunari K, Maeda K, Nakamura M, Yoshikawa J. (2002). Oxidative stress in leukocytes is a possible link between blood pressure, blood glucose, and C-reacting protein. Hypertension, 39(3), 777-80. URL: http://hyper.ahajournals.org/content/39/3/777.long

32. Yousuf O, Mohanty BD, Martin SS, Joshi PH, Blaha MJ, Nasir K, Blumenthal RS, \& Budoff MJ. (2013). High-sensitivity C-reactive protein and cardiovascular disease: a resolute belief or an elusive link? Journal of the American College of Cardiology, 62(5), 397-408. doi:

10.1016/j.jacc.2013.05.016.

URL: http://www.sciencedirect.com/science/article/pii/S073510971302086 $\mathrm{X}$ ?via\%3Dihub 